\title{
Formation of Galactose-1-Phosphate from Uridine Diphosphate Galactose in Erythrocytes from Patients with Galactosemia ${ }^{[3]]}$
}

\author{
Riahard GrtzelmanN ${ }^{[33]}$ \\ Laboratory for Metabolic Research, University Pediatric Department, Kinderspital Zürich, Switzerland
}

\section{Extract}

Erythrocyte lysates of galactosemic patients were found to form galactose-1-phosphate from uridine diphosphate galactose. The enzymatic reaction most likely responsible for this conversion is uridine diphosphate galactose pyrophosphorylase, an enzyme believed to be absent from human erythrocytes, but other reactions might be involved.

\section{Speculation}

Galactose-1-phosphate concentration in red cells of galactosemic infants may prove useless as an indicator of galactose uptake from foodstuffs.

\section{Introduction}

In 1966, a galactosemic baby (R.W.) was admitted to this hospital on the third day of life. A galactoserestricted diet had been prescribed for the mother during the last six months of pregnancy. In the baby's cord blood, no galactose-1-phosphate uridyltransferase was detectable; the amount of galactose-1-P was $8 \mathrm{mg} / 100$ $\mathrm{ml}$ erythrocytes. The baby was given a soybean formula thought to be free of galactose. Unexpectedly, at age 10 days, red cell galactose-1-P had risen to 22 $\mathrm{mg} / 100 \mathrm{ml}$ and continued to oscillate between 9 and $21 \mathrm{mg} / 100 \mathrm{ml}$ during the next 8 weeks. HARRrs and IsBELL [11] have reported a similar case. Galactose contamination of the soybean formula was never ruled out, and the presence of galactose-1-P could have stemmed from galactose via the galactokinase reaction (fig. 1). Formation of red cell galactose-1-P from precursors other than galactose was also considered.

The ability of the red cells of the baby to dispose of accumulated galactose-1-P was investigated. Washed red cells were incubated for two days in a glucosecontaining galactose-free medium, and disappearance of galactose-1-P was followed. For comparison, erythrocytes of the patient's 20-month-old galactosemic sister (B.W.) were exposed in vitro to galactose and, after galactose-1-P accumulation, were incubated in the same manner. The red cells of both children behaved in a strikingly similar way (fig.2). When the medium was renewed at 2 to 3 -hour intervals, galactose-1-P content dropped rapidly; however, when the medium was not changed during 14-hour intervals and the glucose content was depleted, the galactose-1-P content remained constant in the first glucose 'starvation' period. It rose slightly in the second such period, although the medium contained no galactose.

The possible formation of galactose-1-P from uridine diphosphate galactose in galactosemic red cells was also investigated. Synthesis of the phosphate ester would necessarily involve a reaction or reactions other than that catalyzed by galactose-1-phosphate uridyl- 


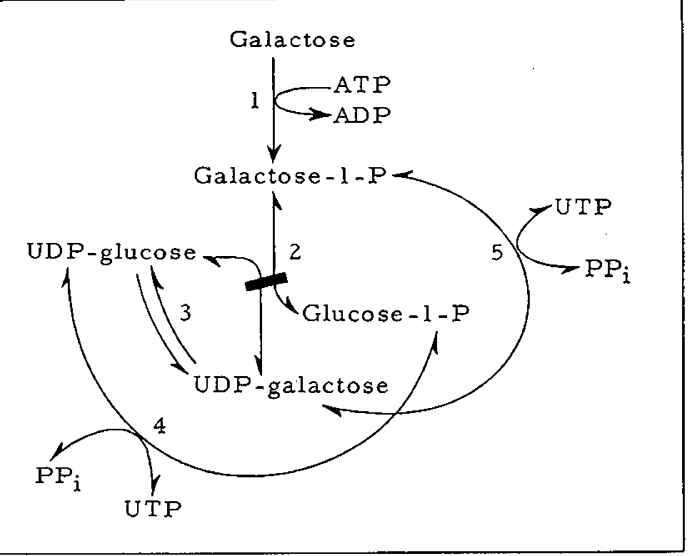

Fig.1. Some reactions of intermediary galactose metabolism, catalized by: 1 . galactokinase, 2 . galactose1-phosphate uridyltransferase (this reaction is blocked in galactosemia), 3. UDP-glucose 4-epimerase, 4. UDP-glucose pyrophosphorylase, 5. UDP-galactose pyrophosphorylase.

$\begin{array}{ll}\text { Abbreviations: } & \\ \text { Galactose-1-P } & \alpha \text {-D-galactose-1-phosphate } \\ \text { Glucose-1-P } & \alpha \text {-D-glucose-1-phosphate } \\ \text { UDP-galactose } & \text { uridine diphosphate galactose } \\ \text { UDP-glucose } & \text { uridine diphosphate glucose } \\ \text { ATP } & \text { adenosine triphosphate } \\ \text { ADP } & \text { adenosine diphosphate } \\ \text { UTP } & \text { uridine triphosphate } \\ \text { UDP } & \text { uridine diphosphate } \\ \text { PP }_{\mathbf{i}} & \text { inorganic pyrophosphate }\end{array}$

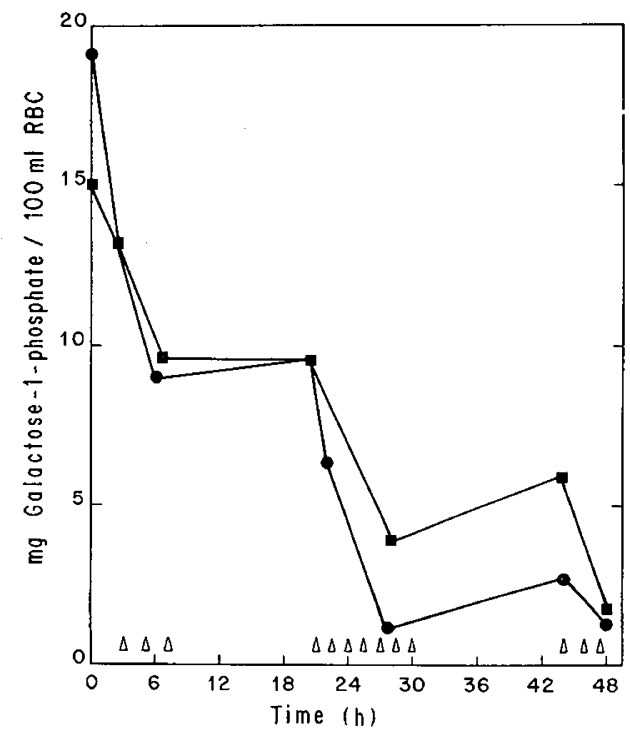

transferase, since this enzyme was absent in the patients. Experimental conditions were especially designed to test the occurrence of the UDP-galactose pyrophosphorylase reaction [1, 12]. The results of these investigations are presented in this study.

\section{Materials and Methods}

Fifteen hemolysates were obtained from five typical galactosemic patients older than 9 months of age. Repeated assays $[2,5]$ of these patients revealed no detectable erythrocyte galactose-1-phosphate uridyltransferase activity, and approximately $50 \%$ activity was found in their parents. Erythrocytes were washed three times with cold $0.154 \mathrm{M} \mathrm{NaCl}$, packed, lysed by freezing, and used immediately or within 5 weeks of storage at $-20^{\circ}$. Sources of the chemicals and enzymes used are listed under 'References and Notes' [27]. Descending paper chromatography of hexoses and hexose phosphates was performed with the following solvents: $n$-propanol/concentrated ammonia/ water, $60 / 30 / 10$ by volume [10], solvent $\mathrm{A}$; tertbutanol/0.1 $\mathrm{N}$ hydrochloric acid, 80/20 v/v [24], solvent $\mathrm{B}$; and ethyl acetate/pyridine/water, $10 / 4 / 3$ by volume, solvent $\mathrm{C}$. Sugars were visualized with aniline phthalate [19], with ammonium molybdate reagent [10], or by autoradiography. Gas liquid chromatography of permethyl-silylated sugars was performed as described previously [8].

Erythrocyte galactose-1-P was estimated enzymatically [14]. Galactose was measured according to the method of Rotн et al. [21], using $0.04 \mathrm{M}$ tris buffer at $\mathrm{pH}$ 8.1. Inorganic and total phosphates were determined by using the method of Bagrnski et al. [3]. Deionization was carried out by passing probes through glass columns filled with alternating layers of Amberlite resin IR-45-AG $(-\mathrm{OH})^{-}$and IR-120-AG $(-\mathrm{H})^{+}$

Fig. 2. Galactose-1-P levels in erythrocytes of galactosemic

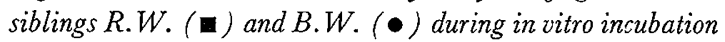
in the presence of glucose as the sole carbohydrate.

Erythrocytes were washed 3 times with cold saline, suspended in 3 volumes of Krebs-Ringer bicarbonate buffer, $\mathrm{pH} 7.4$, containing $100 \mathrm{mg}$ glucose $/ 100 \mathrm{ml}$. The suspensions were transfered into Erlenmeyer flasks which were continually gassed with humidified $\mathrm{CO}_{2} / \mathrm{O}_{2}$ $(95 \% / 5 \%)$ and gently moved in a metabolic shaker at $37^{\circ} \mathrm{C}$. At indicated intervals $(\Delta)$, the buffer was renewed. Erythrocyte aliquots were withdrawn for enzymatic determination of galactose-1-P, and incubation continued with the remaining red cells in renewed medium. Glucose in the supernatant medium was within a $60-100 \mathrm{mg} / 100 \mathrm{ml}$ range after the shorter intervals and $0-15 \mathrm{mg} / 100 \mathrm{ml}$ after the longer intervals. 
[28] or with Retardion 11A8, 50-100 mesh [29], as suggested by Fenton [6].

\section{In Vitro Incubation of Hemolysates with UDP-Galactose}

In order to deplete NAD and thus prevent epimerase reaction [14], hemolysates were preincubated at $37^{\circ}$ for 10 minutes. Fourteen different incubations were carried out using UDP-D-galactose- ${ }^{14} \mathrm{C}$ and $\mathrm{PP}_{\mathrm{i}}$ as substrates. When the reverse reaction was tested, either UTP (one experiment) or galactose-1-P (three experiments) was ${ }^{14} \mathrm{G}$-labeled. Typical reaction mixtures contained UDP-galactose- ${ }^{14} \mathrm{C}, 10 \mu \mathrm{c} / 0.55 \mu$ moles; $\mathrm{PP}_{\mathrm{i}}$, $20 \mu$ moles; $\mathrm{MgCl}_{2}, 10 \mu$ moles; tris buffer $\mathrm{pH} 7.5,60$ $\mu$ moles; and $0.2 \mathrm{ml}$ of hemolysate containing a small amount (0.03-0.05 $\mu$ moles) of galactose-1-P, if any, in one ml. The reaction was started by addition of the hemolysate. To terminate the reaction, tubes were placed in a boiling water bath for 90 seconds and then kept in ice. Supernatants were obtained by centrifugation, and the reaction products were separated by chromatography on either paper or ion exchange columns or both.

Ascending chromatography was performed on Whatman No. 4 paper strips, prewashed with the solvent, and developed with 7.5 volumes of $96 \%$ ethanol plus 3 volumes of $1 \mathrm{M}$ ammonium acetate, $\mathrm{pH} 3.8$, solvent $\mathrm{D}$ [18] for a distance of $22 \mathrm{~cm}$ from the starting point. The strips were air dried and scanned for radioactivity. Sections containing the labeled products were cut out and placed into vials for liquid scintillation counting [22]. Ion exchange chromatography [4] was performed on $1 \times 17 \mathrm{~cm}$ columns containing Dowex 1 (formate form, prepared from Dowex 1-X8 chloride, 200-400 mesh) with a nonlinear gradient of zero to $0.55 \mathrm{~N}$ ammonium formate $\mathrm{pH} 3.67$ buffer at 1 or $2 \mathrm{ml} /$ min. Fractions of $15 \mathrm{ml}$ were collected. For identification of radioactive products, 3 to $5 \mathrm{mg}$ of UDP-galactose and galactose-1-P were added to the filtrates prior to chromatography and were demonstrated in the effluent with the anthrone reaction [15] and by UVabsorbance. Measurements of radioactivity in the effluents were made by liquid scintillation spectrometry [20], using toluene- ${ }^{14} \mathrm{C}$ internal standards for determining counting efficiencies. Reaction velocity was calculated from the proportions of radioactivity in the reaction products.

\section{Results}

\section{Formation of Galactose-1-P from UDP-Galactose by} Galactosemic Hemolysates; Characterization of the Reaction Product

When hemolysates from patients were incubated in the presence of ${ }^{14} \mathrm{C}$-labeled UDP-galactose under standard conditions, a newly formed radioactive intermediate thought to be galactose-1-P was observed and characterized as follows.

Deproteinized reaction mixtures were subjected to ascending paper chromatography (solvent D), and sections containing the presumed galactose-1-P were eluted with $\mathrm{H}_{2} \mathrm{O}$ in the cold. Eluates were concentrated in vacuo and served as the substrate in the modified Warburg procedure [26], using as the enzyme source whole blood lysates of the following: healthy controls, a galactokinase-deficient man [7], and several galactosemic patients. Production of ${ }^{14} \mathrm{CO}_{2}$ was significant in the vials containing blood of healthy controls and of the galactokinase-deficient man, but was approximately 10 times smaller in vials containing blood of galactosemic patients, that is, of individuals with expected inability to metabolize galactose-1-P.

Similarly prepared eluates containing negligible amounts of UV-absorbing material (at $260 \mathrm{~nm}$ ) were subjected to paper chromatography analysis, using solvents A or B. Radioactivity co-chromatographed with added labeled galactose-1-P, but not with galactose-6-P or 1,6-diphosphate.

When initial reaction products were separated by column chromatography on Dowex (fig. 3), fractions containing the presumed galactose-1-P were pooled, concentrated to a few $\mathrm{ml}$ in a rotary evaporator at $38^{\circ}$, diluted and reconcentrated several times. They were then subjected to a high vacuum overnight, and finally made up to a volume of 0.5 or $1.0 \mathrm{ml}$ with water. These preparations are termed concentrates. Two-dimensional chromatograms of concentrates were developed using solvents A and B. Radioactivity was limited in a single spot that co-chromatographed with galactose1-P and was clearly separated from galactose-6-P and 1,6-diphosphate; glucose-1-P, glucose-6-P, glucose1,6-diphosphate; and fructose-1-P.

Concentrates were hydrolyzed for 10 minutes in $0.05 \mathrm{~N} \mathrm{HCl}$ at $100^{\circ}$; aliquots were withdrawn, chilled, neutralized, and deionized by passage through Retardion columns. Radioactivity was measured in the effluents. Apparent hydrolysis of the probe proceeded at the same rate as that of the separately treated authentic galactose-1-P. At this step, deionization was omitted, and the effect of hydrolysis was examined by determining inorganic phosphate. Galactose-6-P was not hydrolyzed appreciably under the same conditions.

Acid hydrolysis in $0.05 \mathrm{~N} \mathrm{HCl}$ at $100^{\circ}$ was also performed after addition of unlabeled galactose-1-P to the concentrates. Figure 4 shows a typical result. The parallel appearance of galactose and radioactivity indicated an identical rate of hydrolysis of the authentic galactose-1-P and of the prepared reaction product.

Galactose oxidase was found to oxidize some substrate contained in the concentrates rather slowly, but 
ready oxidation was observed when alkaline phosphatase was added to the reaction mixture. Galactose and total phosphate were present in a molar ratio of $1: 1.36$; it is possible that phosphate esters other than galactose1-P were also present.

After 2-dimensional paper chromatography of the concentrates, the ratio of galactose to phosphate was approximately $2: 1$, and the radioactive substance eluted from the paper was readily oxidized by galactose oxidase even in the absence of phosphatase; this finding was thought to indicate that hydrolysis had occurred during chromatography. Eluates from the paper were ninhydrine-negative; after acid hydrolysis, gas chromatography revealed the presence of 1 part glucose in 2.5 parts galactose in this eluate. The radioactive label appeared only in galactose (paper chromatography, solvent C).

Thus, identity of the reaction product with galactose1-P was established. The hexose moiety of the UDPgalactose fractions separated on paper or on Dowex resin was analyzed repeatedly; the ${ }^{14} \mathrm{C}$-label was always detected in galactose and never in glucose. In the deproteinized reaction mixtures separated by either paper or column chromatography, free ${ }^{14} \mathrm{C}$-galactose was never detected.

\section{Formation of Galactose-I-P from UDP-Galactose by Galactosemic Hemolysate; Reaction Conditions}

Formation of galactose-1-P proceeded in the manner of an enzymatic reaction. Omission of the hemolysate prevented the reaction, but addition of hemolysate started the reaction immediately. The time course of such an experiment is shown in figure 5. In most experiments, the apparent reaction equilibrium was reached within 60 to 100 minutes; at this point, addition of more pyrophosphate or uridine diphosphate galactose did not carry the reaction any farther, possibly because of enzyme inactivation. Apparent initial reaction rate was proportional to the amount of hemolysate present in the reaction mixture (fig.6). Pyrophosphate concentration was critical. When $\mathrm{PP}_{\mathbf{i}}$ was excluded from the reaction mixtures, no galactose-1-P was formed, but an unidentified product containing ${ }^{14} \mathrm{C}$-labeled galactose (5-15\% of the radioactivity present initially) appeared within the first 20 seconds of incubation; this component was eluted from Dowex 1 (formate) columns immediately after galactose-1-P and had slightly higher mobility than galactose-1-P on paper chromatograms (solvent $\mathrm{D}$ ). Doubling the standard $\mathrm{PP}_{\mathrm{i}}$ concentration of $2 \times 10^{-2} \mathrm{M}$ reduced the activity to approximately $20 \%$, and at $0.2 \times 10^{-2} \mathrm{M}$, galactose1-P formation was reduced to $1.5 \%$. When $\mathrm{Mg}^{+}+$was omitted from the reaction mixture, galactose-1-P formation was barely detectable. At pH 5.1 (0.06 M sodium acetate buffer), the reaction proceeded very

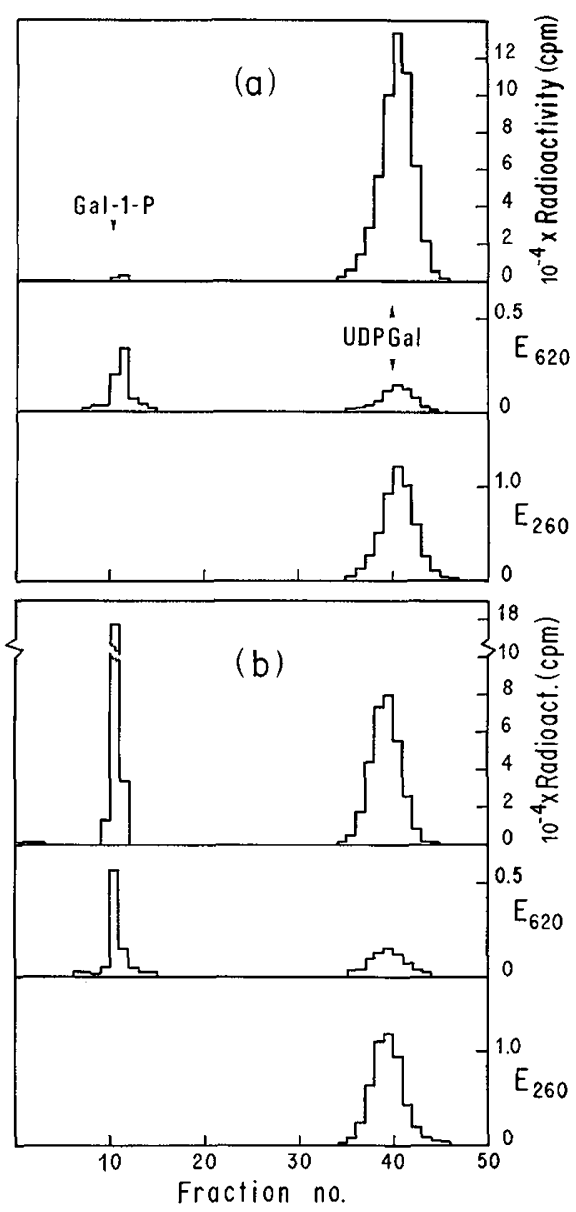

Fig.3. Dowex 1 (formate) elution pattern of reaction mixtures deproteinized after incubation of a patient's erythrocyte lysate with UDP-galactose and $\mathrm{PP}_{\mathrm{i}}$ as substrates, for $20 \mathrm{sec}$ (a) and $20 \mathrm{~min}$ (b). $0.03 \mu$ moles of galactose-1-P from $0.2 \mathrm{ml}$ of hemolysate were present initially in one $\mathrm{ml}$ of standard reaction mixture. Prior to chromatography, $5 \mathrm{mg}$ of non-labeled UDP-galactose and of galactose-1-P were added to each filtrate. Fraction volume was $15 \mathrm{ml}$. Radioactivity was followed throughout, anthrone reaction $\left(\mathrm{E}_{620}\right)$ and UV-absorption through the radioactive regions.

Fig. 5. Formation of galactose-1-P from UDP-galactose by erythrocyte lysate of a galactosemic patient during a 4 hours incubation. One $\mathrm{ml}$ of reaction mixture contained UDP-galactose- ${ }^{14} \mathrm{C} 4 \mu \mathrm{c} / 0.55 \mu$ moles, $\mathrm{PP}_{\mathrm{i}} 20$ $\mu$ moles, $\mathrm{MgCl}_{2} 10 \mu$ moles; Tris-HCl (pH 7.5) 60 $\mu$ moles; and $0.2 \mathrm{ml}$ lysate containing no galactose-1-P. Reaction products were separated by paper chromatography. 


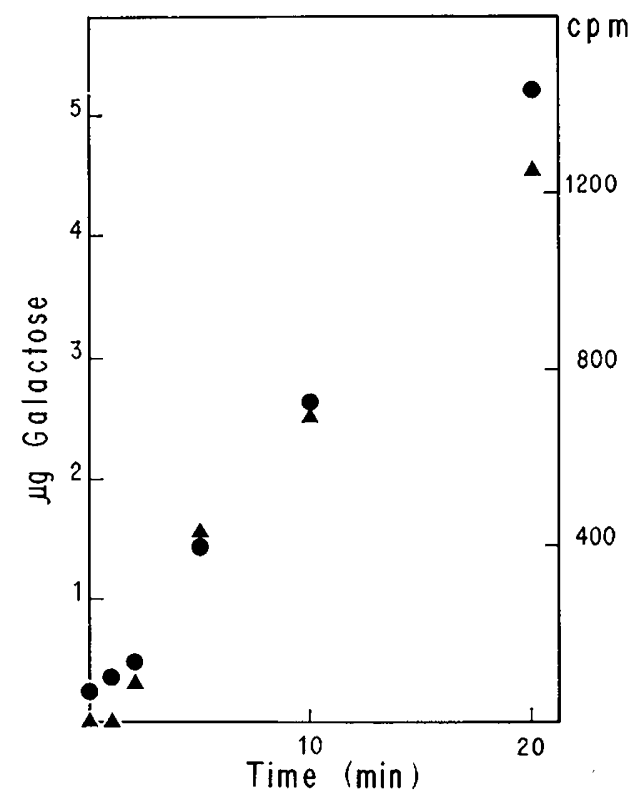

Fig.4. Acid hydrolysis $\left(0.05 \mathrm{~N} \mathrm{HCl}, 100^{\circ}\right)$ of reaction product prepared by ion exchange chromatography on Dowex 1 (formate) followed by 2-dimensional paper chromatography. Prior to hydrolysis, non-labeled galactose-1-P was added. Galactose $(\boldsymbol{\Lambda})$ and radioactivity $(\bullet)$ were measured.

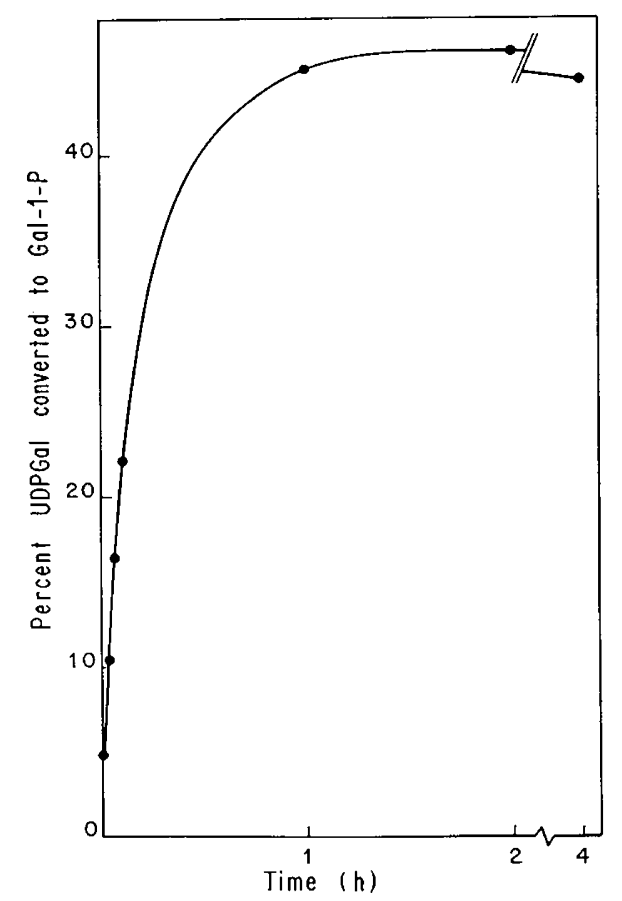

Fig.5. (Legend see page 282.)

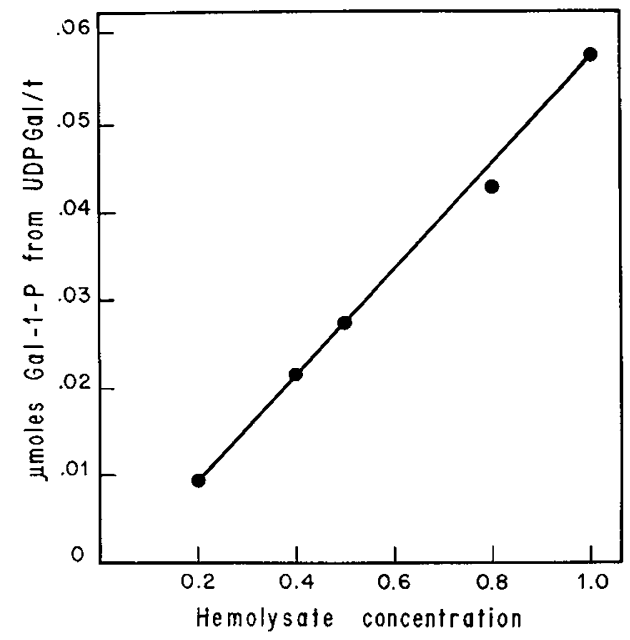

Fig. 6. Formation of galactose-1-P from UDP-galactose by erythrocyte lysate of a galactosemic patient. 'Enzyme' velocity curve. Various amounts of hemolysate free of galactose-1-P in standard reaction mixture were used. Incubations were carried out over $51 / 2 \mathrm{~min}$; 4 measurements were taken at $90 \mathrm{sec}$ intervals. Reaction products were separated by ion exchange chromatography.

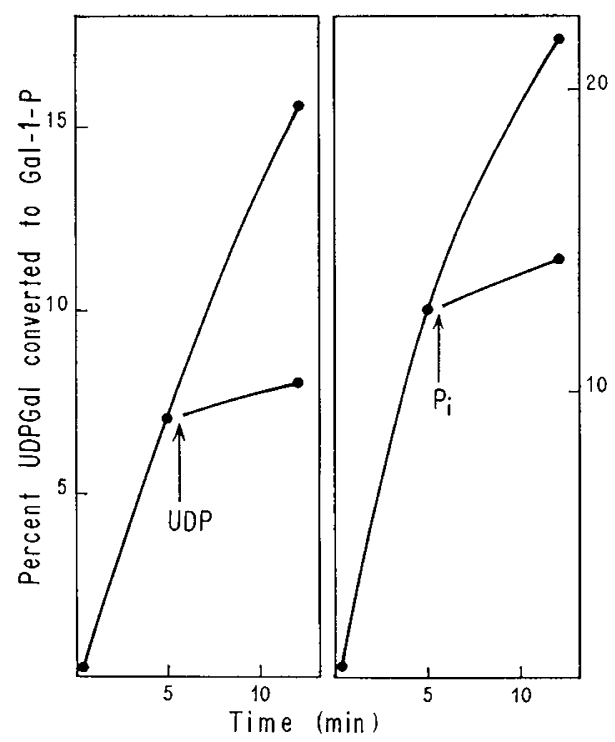

Fig.7. Inhibition of galactose-1-P formation from UDPgalactose in galactosemic hemolysates. Standard reaction mixtures were employed. Initial concentrations were $0.5 \times 10^{-3} \mathrm{M}$ UDP-galactose and $2.0 \times 10^{-2} \mathrm{M}$ $\mathrm{PP}_{\mathrm{i}}$. Inhibitors were added after $5 \mathrm{~min}$ to a final concentration of $5.0 \times 10^{-2} \mathrm{M}$ UDP and $5.8 \times 10^{-2} \mathrm{M} \mathrm{P}_{\mathrm{i}}$. 
slowly in the presence of $\mathrm{Mg}^{++}$, but did not take place at all when $\mathrm{Mg}^{++}$was replaced by $\mathrm{Co}^{++}$.

Since, at this point, it seemed likely that the in vitro production of galactose-1-P was due to pyrophosphorolysis of UDP-galactose, possible inhibitors [1, 25] of the UDP-galactose pyrophosphorylase reaction were tested. Inorganic phosphate and UDP were added to standard mixtures after the reaction had proceeded for 5 minutes and were found to reduce markedly the rate of galactose-1-P formation (fig. 7). MgUDP and $\mathrm{MgADP}$ were also inhibitory. When equimolar concentrations of UDP-glucose were present at the start of the incubation, appearance of galactose-1-P from UDP-galactose was reduced by 55 percent.

In control experiments, erythrocyte lysates of normal subjects incubated under identical conditions produced ${ }^{14} \mathrm{C}$-galactose-1-P from UDP-galactose-14 $\mathrm{C}$ at about the same rate as did the hemolysates of galactosemic patients. The effecis of omission of $\mathrm{PP}_{\mathrm{i}}$ or $\mathrm{Mg}++$ were not tested.

\section{Reversal of the Reaction}

In only a few experiments, erythrocyte lysates of galactosemic patients and of normal subjects were reacted with ${ }^{14} \mathrm{C}$-galactose-1-P during a one-hour period. One $\mathrm{ml}$ of reaction mixture contained galactose1 -P, $5 \mu$ moles; UTP, $5 \mu$ moles; $\mathrm{MgCl}_{2}$, $15 \mu$ moles; tris buffer $\mathrm{pH} 7.5,30 \mu$ moles; and $0.25 \mathrm{ml}$ of hemolysate. Reaction products were again separated by ion exchange column chromatography. Galactosemic lysates produced a number of labeled intermediates, one of which was eluted from the column in the UDPhexose region but remained on the column somewhat longer than did authentic UDP-galactose and overlapped with it. This fraction contained only a small percent of the total radioactivity recovered. Normal hemolysates produced only traces of the same intermediate. When ${ }^{14} \mathrm{C}$-UTP was used as the substrate, a similar intermediate was eluted from the column. Because of the small amount of this labeled intermediate, no attempts at purification and analysis were made. Thus, reversal of the reaction was not demonstrated convincingly.

\section{Discussion}

As had been suspected, hemolysates of galactosemic patients, that is, individuals lacking appreciable galactose-1-phosphate uridyltransferase activity, proved capable of forming galactose-1-P from UDP-galactose in vitro. The identity of the labeled reaction product with galactose-1-P was established. In view of the ready formation of this phosphate ester by hemolysates and of the observed rise of galactose-1-P in galactose- free medium (fig.2), it can be assumed that erythrocytes of galactosemic patients will also, under suitable conditions, form galactose-1-P from UDP-galactose in vivo. Since UDP-glucose 4-epimerase is active from early embryonic stages in man [30], UDP-galactose is also supplied as the precursor of such galactose-1-P.

In the present study, the reaction of UDP-galactose to galactose-1-P proceeded at an initial rate of up to $4.8 \mu \mathrm{moles} / \mathrm{h} / \mathrm{ml}$ erythrocytes, calculated from the experiment shown in figure 5 . Several possible enzymatic reactions by which galactose-1-P could arise from UDP-galactose must be considered. First, galactose-1phosphate uridyltransferase action can be ruled out. The presence of residual transferase activity in galactosemic hemolysates had been reported by NG et al. [16] to explain formation of small amounts of UDP-hexose from galactose-1-P. If, in the experiments performed in the present study, reversal of the galactose-1-phosphate uridyltransferase reaction had produced the galactose-1-phosphate, substantial transferase activity should have been found in the hemolysates.

Direct sugar release from guanosine nucleotide has been described by SonNino et al. [23]; this novel hydrolytic reaction in yeast proceeded according to the following formula:

\section{(1) GDP-glucose $+\mathrm{H}_{2} \mathrm{O} \rightarrow \mathrm{GDP}+$ glucose}

In the galactosemic hemolysates, UDP-galactose could not have been hydrolyzed similarly, since phosphorylation of liberated galactose would not have exceeded a rate of $0.5 \mu$ moles $/ \mathrm{h} / \mathrm{ml}$ red blood cells, the normal rate of galactokinase reaction in red cells [7, 17]. Furthermore, free ${ }^{14} \mathrm{C}$-labeled galactose would have been detected.

Another type of nucleoside diphosphate sugar hydrolase has been characterized by GLAser et al. [9]. In some bacteria, this UDP-sugar hydrolase catalyzes the breakdown of UDP-glucose:

(2) UDP-glucose-+E $\rightarrow$ UDP-glucose-E $\underset{\searrow \text { E-UMP }}{\nearrow \text { glucose-1-P }}$

Such a reaction has not been described in mammals, but it could have occurred in the experiments described above. The fact that at $\mathrm{pH} 5.1$, formation of galactose1-P was minimal and that at this $\mathrm{pH}, \mathrm{Co}++$ could not replace $\mathrm{Mg}++$ as it does in the bacterial enzyme, does not preclude this possibility since a mammalian enzyme could have different properties.

Still, theUDP-galactose pyrophosphorylase reaction:

(3) UDP-galactose + PPi $\rightleftharpoons$ galactose-1-P + UTP

would provide the most likely explanation for the formation of galactose-1-P from UDP-galactose in galactosemic hemolysates as reported here. There was pyrophosphate dependence as well as a $\mathrm{Mg}^{++}$require- 
ment; UDP, $\mathrm{P}_{\mathrm{i}}$ and UDP-glucose were inhibitory; at $\mathrm{pH}$ 5.1, the reaction proceeded very slowly.

In human red cells, UDP-glucose pyrophosphorylase is active [2], but UDP-galactose pyrophosphorylase has been believed to be absent [13]. Recently, however, evidence for the common identity of these enzymes, at least in calf liver, has been presented [25]. In view of this new evidence and in order to adequately explain the results of the present study, reexamination of human red cells for the presence of UDP-galactose pyrophosphorylase is necessary.

Elevated levels of erythrocyte galactose-1-P in treated galactosemic patients have been believed to indicate that galactose has been taken up from foodstuffs. It now appears that galactose-1-P in erythrocytes may have an endogenous origin. The possibility cannot be excluded that galactose deprivation in the mother during pregnancy may create in the mother and the susceptible infant a peculiar metabolic situation manifest after birth as a high rate of UDP-hexose to galactose-1-P conversion in the red cells of the newborn.

\section{References and Notes}

1. Albreght, G.J.; Bass, S.T.; Seifert, L.L. and HANSEN, R.G.: Crystallization and properties of uridine diphosphate glucose pyrophosphorylase from liver. J. biol. Chem. 241: 2968 (1966).

2. Anderson, E. P.; Kalckar, H.M.; Kurahashi, K. and IsSELBACHER, K.J.: A specific enzymatic assay for the diagnosis of congenital galactosemia. J.Lab. clin. Med. 50: 469 (1957).

3. BAGInskr, E.S.; Foג̀, P.P. and ZAK, B.: Microdetermination of inorganic phosphate, phospholipids, and total phosphate in biologic materials. Clin. Chem. 13: 326 (1967).

4. Bartlett, G.R.: Methods for the isolation of glycolytic intermediates by column chromatography with ion exchange resins. J. biol. Chem. 234: 459 (1959).

5. Beutler, E. and Baluda, M. C.: Improved method for measuring galactose-1-phosphate uridyl transferase activity of erythrocytes. Clin.chim. Acta 13: 369 (1966).

6. Fenton, J.C.B.: The estimation of galactose-1phosphate in red cells. Clin. chim. Acta 11: 205 (1965).

7. Grtzelmann, R.: Hereditary galactokinase deficiency, a newly recognized cause of juvenile cataracts. Pediat. Res. 1: 14 (1967).

8. Grtzelmann, R.; Gurtius, H. C. and Müller, M. : Galactitol in the urine of a galactokinase deficient man. Biochem. biophys. Res. Commun. 22: 437 (1966).
9. Glaser, L.; Melo, A. and Paul, R.: Uridine diphosphate sugar hydrolase. Purification of enzyme and protein inhibitor. J. biol. Chem. 242: 1944 (1967).

10. HANEs, C.S. and Isherwood, F. A.: Separation of the phosphoric esters on the filter paper chromatogram. Nature, Lond. 164: 1107 (1949).

11. Harris, R.C. and Isbell, S.V.: Galactose-1phosphate accumulation in red cells of a neonate. Abstr. Soc. Pediat. Res.; Pediat. Res. 1: 200 (1967).

12. Isselbacher, K.J.: A mammalian uridinediphosphate galactose pyrophosphorylase. J. biol. Chem. 232: 429 (1958).

13. Isselbacher, K.J.: Galactosemia; in: The metabolic basis of inherited disease (ed. STANBURY, J. B.; WYNGAARDEN, J. B. and FREDRIGKSON, D. S.), p.178 (McGraw-Hill, New York 1966).

14. Kirkman, H.N. and Maxwell, E. S.: Enzymatic estimation of erythrocytic galactose-1-phosphate. J.Lab. clin. Med. 56: 161 (1960).

15. Morris, D.L.: Quantitative determination of carbohydrates with Dreywood's anthrone reagent. Science 107: 254 (1948).

16. NG, W.G.; Bergren, W.R. and Donnell, G.N.: Galactose-1-phosphate uridyl transferase activity in galactosemia. Nature, Lond. 203: 845 (1964).

17. NG, W. G.; Donneli, G.N. and Bergren, W.R.: Galactokinase activity in human erythrocytes of individuals at different ages. J.Lab.clin. Med. 66: 115 (1965).

18. PALAdini, A.C. and Lelorr, L.F.: Studies on uridine-diphosphate-glucose. Biochem. J. 51: 426 (1952).

19. Partridge, S. M.: Aniline hydrogen phthalate as a spraying reagent for chromatography of sugars. Nature, Lond. 164: 443 (1949).

20. Patrerson, M.S. and Greene, R.C.: Measurement of low energy beta-emitters in aqueous solution by liquid scintillation counting of emulsions. Anal. Chem. 37: 854 (1965).

21. Roth, H.; SegAL, S. and Bertoli, D.: The quantitative determination of galactose. An enzymic method using galactose oxidase, with applications to blood and other biological fluids. Anal. Biochem. 10: 32 (1965).

22. Syerman, J.R.: Rapid enzyme assay technique utilizing radioactive substrate, ion-exchange paper, and liquid scintillation counting. Anal. Biochem. 5: 548 (1963).

23. Sonnino, S.; Carminattr, H. and Cabib, E. : Direct release of sugar from a sugar nucleotide. A novel enzymatic reaction. J. biol. Chem. 241: 1009 (1966).

24. Steinitz, K.: Detection and identification or fructose 1-phosphate by paper chromatography. Anal. Biochem. 2: 497 (1961). 
25. Ting, W.K. and HANSEN, R. G.: Uridine diphosphate galactose pyrophosphorylase from calf liver. Proc. Soc. exp. Biol. N.Y. 127: 960 (1968).

26. WeinberG, A.N.: Detection of congenital galactosemia and the carrier state using galactose $\mathrm{C}^{14}$ and blood cells. Metabolism 10: 728 (1961).

27. UDP-D-galactose- ${ }^{-14} \mathrm{C}$ (D-galactose- ${ }^{14} \mathrm{C}$, u.l.) and Uridine ${ }^{14} \mathrm{C}$ (u.l.)- 5'triphosphate, New England Nuclear Corp., Boston, Mass.; D-galactose-1phosphate- ${ }^{14} \mathrm{C}$ (u.I.), International Chemical and Nuclear Corp., City of Industry, California; $\alpha$-Dgalactose-1-P, UDP-galactose, UTP and tetrasodium pyrophosphate, Sigma Chemical Co., St. Louis, Mo.; mold galactose oxidase, Miles Laboratories, Elkhart, Ind.; horse radish peroxidase and calf intestinal alkaline phosphatase, Boehringer, Mannheim, Germany.

28. British Drug Houses, Poole, England.

29. Biorad, Los Angeles, Cal.

30. Unpublished observation.

31. Supported in part by Julius Klaus-Stiftung, Zürich, and by Hartmann Müller Stiftung für medizinische Forschung, Zürich.

32. I wish to thank Drs. S. Segal and R.G.HANSEN for valuable advice and comments.

33. Requests for reprints should be addressed to: RIchard Gitzelmann, M.D., Laboratory for Metabolic Research, University Pediatric Department, Steinwiesstrasse 75, 8032 Zürich (Switzerland). 